\title{
XXV. Description of the arseniates of copper and of iron
}

\section{Count de Bournon Smith Barton M.D.}

To cite this article: Count de Bournon Smith Barton M.D. (1802) XXV. Description of the arseniates of copper and of iron , Philosophical Magazine Series 1, 12:46, 135-141, DOI: $10.1080 / 14786440208676039$

To link to this article: http://dx.doi.org/10.1080/14786440208676039

曲 Published online: 18 May 2009.

Submit your article to this journal $\sqsubset \pi$

Џ Article views: 2

Q View related articles $\sqsubset$ 
where improvements are ftill very imperfect, it cannot be deemed a trivial talk to have pointed out fome of thofe vegetables from which an injurious honey is obtaine

The ancients, who, in fome refpects at leaft, were equal to the moderns, appear to have paid much attention to this fubject. Virgil* and Columella have both told us what plants ought to grow about apiaries. It is unneceffary to repeat, in this place, what the two Roman writers have faid on the fubject. The Georgics of the Mantuan poet are in the hands of every man of tafte; and the work of Columellat fould be read, wherever agriculture engages the attention of gentlemen.

The proper management of bees may be confidered as a fcience. It is not fufficient that bees merely make honey and wax. Their honey may be injurious or poifonons, and their wax may be nearly.ufelefs. To affift and to direct the labours of thefe little infects, the knowledge and the hand of man are required. "Let, then, this interefted being be at leaft attentive to his own benefits and pleafures. Let him carefully remove from about the habitations of his bees every fetid or poifonous vegetable, however comely its colour or its form. In particular, let him be careful to remove thofe vegetables which are noxious to himfelf. In place of thefe, let him fpread the " marjoram and thyme," and other plants, " the love of beest," and his labours will be rewarded. He may, then, furrifh his table with an honey not inferior to that of Mount Hermettas, or of Athens; nor to that of Sicily, to which Virgil has fo handfomely alluded in the feventh Eclogue :

Nerine Galatea, thymo mihi dulcior Hyble,

Candidior cycnis, hedera tormofior albâ.

L. $37,3^{8}$.

XXV. Defcription of the Arfeniates of Copper and of Iron. By the Count de Bou R von.

[Concluded from p. 12.]

$\mathrm{T}$

$H E$ modification which we have juft feen the primitive cryttal affume at one of its folid angles, and only on one fide, fometimes takes place alfo (only on one fide) at its two other angles. Then, if the act of cryftallization has continued fo long, under the fame mode of increafe, that the new

* See Georgirorum lib. iv. 1. 30-32.

+ De Re Ruftica, libri xii.

I Amitroig. 
edges, as $A B$, (fig. ${ }^{5}$.) produced by the replacing of the folid angles, unite together, and give birth to a new equilateral triangle, placed in a direction contrary to the primitive one; and if, at the fame time, the cryttal has fuch a length that the fecondary planes terminate at the oppofite bafe, and are very acute if ofceles triangles, the cryftal will prefent the appearance of a kind of truncated hexaedral pyramid, the bafe and apex of which will be equilateral triangles. (fig. I8. Pl. IV.) The fix triangular planes which compofe the pyramid of this cryftal, are always acute ifofceles triangles; but three of them have their acute angle much fmaller than the three others. The fides of the bafe of this kind of pyramid are oppofite to the leaft acute angles; and its truncated apex is oppofite to the moft acute ones; the triangular planes being placed alternately in an oppofite direction. I have feen feveral inftances of this form; but I never faw fuch intermediate varieties as the fecondary plane, reprefented by the dotted lines in fig. I5. would give, if it exifted at the fame time in the three angles.

By a longer duration of the act of cryftallization, under the fame modification, the plane correfponding to the truncated apex of the pyramid (fig. I8.) becomes progreffively fmaller; the moft acute ifofceles triangular planes, which anfwer to the feconddry ones, encroach on the leaft acute, all which are the primitive planes of the cryftal, and the pyramid becomes truly triedral at, its upper extremity, whilft it remains hexaedral at the bafe, on account of thofe parts of the three planes of the primitive cryftal which are fill preferved. (Fig. 19.)

By a fill more confiderable duration of the act of cryftallization, the pyramid would become completely triedral, and would not be truncated at its apex. I have never met with this modification fo complete; but $\mathrm{I}$ have feen the variety reprefented in fig. 19; which, however, as well as fig. 18. is very uncommon.

The triedral prifm is fubject to a fourth modification, which takes place at the three edges of one of its two bafes or terminal furfaces only, and replaces each of thofe edges by a plane, much more inclined on the fide of the prifm on which it is placed than on the terminal furface. (Fig. 20.) I have not been able to determine, in thefe cryftals, the angles formed by thefe new planes, either with the fides of the prifm or with the terminal furfaces; but the varieties belonging to this modification demonftrate that thefe angles are the fame as thofe which the fecondary planes of the folid angles make, either with the terminal furfaces, or with the edges 
edges of the prifm on which they are inclined. When thefe new planes have acquired an increafe of fufficient extent to make the primitive planes of the prifm totally difappear, and to replace them, the cryftal is changed to a triedral pyramid with a truncated apex; the bale and truncated apex of which are equilateral triangles. (Fig. 21.) When it happens that the cryltal has, at the fame time, gone through this modification and that which replaces the folid angles of its other extremity, and thefe two modifications have commenced at the very origin of the formation of the cryftal, there is a particular period of its progrefs, in which the cryftal is lengthened into a hexaedral prifm, with acute triangular ifofceles planes, having for their bafes two equilateral triangular plancs, perfectly equal. (Fig. 22.) After this period, if the act of cryftallization continues, the cryftal affumes the appearance of an extremely acute rhomboid, the acute folid angles of which are replaced, more or lefs completely, by an equilateral triangular plane, (fig. 23.) and finithes at lat by taking the form of a perfect rhomboid. (Fig. 24.)

All thefe varieties, though lefs common than thofe of the firft modification, are yet frequently to be met with, excepting that of fig. 22. which is extremely rare, and of which I have feen only two or three cryftals: in general, however, the cryftals of thefe varieties are very fmall, and their form cannot be well feen without the affiftance of a magnifying glass.

It frequently happens that two of the elongated triedral prifms (fig. 10.) are clofely united to each other by one of the fides of the prifm; whence refults a kind of macle (fig. 25.) the form of which is a rhomboidal tetraedral prifm of $50^{\circ}$ and $120^{\circ}$; but there is always difcernible, on the terminal furfaces of thefe prifins, a very fine tranfverfe line, $A B$, on the fmall diagonal of the rhomboidal plane of thefe furfaces; this line thows the place of union of the two cryftals of which the macle confifts.

Sometimes the two component cryftals of this kind of macle belong to the triedral prifm, which has a fecondary plane in the place of one of its edges; it then has the form either of a hexaedral prifm that has four of its fides (two and two in oppofition) broader than the others (fig. 26.), or of one that has only two oppofite fides broader (fig. 27.), or of a regular one, according to the width of the fecondary planes : in all thefe forms, the line $A B$, indicating the place of union of the two cryltals, is perceptible.

It is not very common, as I have already obferved, to 
meet with fpecimens of this fpecies in which the cryftals ate fufficiently detached to let their form be diftinctly feen. In general, the cryftals are grouped together in great numbers, and feem to penetrate each other, fo as to form mamilla, more or lefs round; or they form a kind of indented cylinders, which have fome refemblance to the trundle of a mill. In that cafe, the part of the cryftals which appears at the furface of thefe aggregations, commonly belongs to one of the fides of their prifm, either the broad or the narrow one. But, when thefe aggregations form either a kind of cylinders, or of mamillæ in clufters diverging like a fan, there may be feen, at the two edges of the cylinder, or at the fummit of the clufters, the whole of the equilateral triangular terminal planes, or trapezia, of one part of the component cryftals.

The fpecific gravity of this fpecies of arfeniate of copper is nearly the fame as that of the preceding one; I found it to be 4,280 . Its hardnefs, however, is not fo great; it is with difficulty that it can be made to fcratch calcareous fpar.

The cryftals of this fpecies, when they have not undergone any change, are tranfparent, and of a very beautiful blueithgreen colour, or dcep verdigrife; but their furface eafily becomes decompofed, and turns black; the cryftals are then totally opaque. It is indeed very feldom, and only in cavities recently expofed, that cryftals can be found which retain their tranfparency and colour. Yet, as the change they undergo commonly takes place only at the furface, rarely penetrating to any great depth, their original colour may eafily be reftored, merely by flightly fcraping the furface with a harp inftrument.

The above is the only change I have had occafion to remark in this fpecies.

Sometimes, but very rarely, this fpecies is found in the orm of fmall hair pencils, with very delicate fibres ; and as, in the fpecimens in which $I$ obferved this variety, the little fbrous tuft had preferved its beauliful verdigrife colour, nothing could exceed the beauty of their appearance.

I have likewife obferved this fpecies in a mamillary form, with a compact texture; but this variety, like the preceding, is extremely rare.

The matrix of this arfeniate of copper is the fame as that of all the preceding fpecies; and that fpecies which is moft frequently found with it, is the arfeniate in obtufe octaedra. It is alfo frequently accompanied with that kind of ore which is known by the name of azure copper ore. 


\section{SECTION II.}

\section{Arfeniates of Iron.}

Muttrell mine, which is immediately contiguous to Huel Gorland mine, in the county of Cornwall, has produced fome fpecimens of arfeniates of copper exactly fimilar to thofe defcribed in the former part of this paper. But this mine is ftill more interefting to mineralogifts, on account of a combination found therein, of arfenic acid with iron, and alfo a double combination of that acid with both iron and copper.

The firtt-mentioned of thefe arfeniates feems analogous to thofe cryftals, or cubes, of a fine green colour, of which fome fpecimeus had alreadv been found in Carrarach and Tincroft mines, and which Klaproth, in his Memoir upon the Mineralogy of Cornwall, confidered as belonging to the arfeniates of copper; but, according to the analyfis made by $\mathrm{Mr}$. Chenevix, with all the care which his extenfive knowledge and extreme zeal for feience would naturally lead him to employ, it appears to be a true arfeniate of iron, containing only a fmall quantity of copper; and even that quantity feems to be merely an accidental mixture. As, in the fpecimens from the old mines of Tincroft and Carrarach, the greateft part of the cryftals adhered to vitreous gray copper ore, it is poffible that fome particles of that ore remained attached to the cryftals; or, as $I$ have frequently found to be the cafe, that fome fuch particles had penetrated into the cryftals, and that Mr. Klaproth had been thereby deceived, by finding in the button left by the blowpipe a much greater proportion of copper than this ore really contains. The natural decompofition of this arfeniate, which produces an oxide of iron of a fine reddifh yellow colour, ftrongly confirms the refult of Mr. Chenevix's analyfis.

Gmelin, in his Principles of Mineralogy, printed at Göttingen in the year $179^{\circ}$, had already fuppofed that thefe cryftals could not belong to the fubftance which, in mineralogical publications, had been called arfenical copper ore. He had confequently feparated them, leaving them, however, among the ores of copper, inder the name of rusirfel crtz.

The double combination of the arfenic acid with iron and copper, although it had appeared to exift in the arfeniate juft fpoken of, in the mirtes of Tincroft and Carrarach, had not excited the attention of mineralogifts. It is however poffible that the tranfparency, the brilliancy, and the pale blue colour of its cryftals, might occafon them to be miftaken for cryftals of a tony natue. Befides, their fmalinefs might eafily 
eafily caufe them to efeape the notice of common obfervattion, particularly when they are not in pretty large groups.

The matrix of thefe two arfeniates is exactly the fame as that of the arfeniates of copper; confifting, like that, of quartz, mixed with yellow, gray, and vitreous ores of cop: per, with oxides of iron, and with mifpickel. The mines of Huel Gorland and Muttrell, although not fituated in the diftrict of the tin mines, have yet produced fome fpecimens of tin, the cryftals of which are covered with thofe of the arfeniate here fpoken of. Two fpecimens of this kind are in the collection of Sir John St. Aubyn.

\section{Species I. Simple Arfeniate of Iron.}

This fpecies cryftallizes in perfect cubes, (fig. 28.); fometimes, though rarely, they are a little flattened; their fides are fmooth and brilliant.

The only modification I have obferved in this form is, that four of the eight folid angles of the cube are replaced by an equal number of equilateral triangular planes, fituated in fuch a manner, that every one of the fides of the cube becomes an elongated hexagon, having two angles of $90^{\circ} \mathrm{each}$, and four of $135^{\circ}$. (Fig. 29.) Cryftals modified in this way are very fcarce. I have never feen but one fuch fpecimen, which is in the collection of Sir John St. Aubyn. The cryftals of it are pretty large, and very well defined.

The fpecific gravity of this fpecies is 3,000 . Its hardnefs is juft fufficient to fcratch calcareous fpar. Its cryftals, which are tolerably tranfparent, are of a dark green colour, with a brownith tinge; fometimes they are rather yellowifh; and there exift fome fpecimens of a brown yellow colour like refin. I have never feen this fpecies in any other fate than that of perfect cryftallization.

Sometimes, indeed, a decompofition takes place, which caufes the cryitals to pafs into the ftate of a pulverulent oxide, of a fine reddith yellow colour. In this cafe, as the bulk of the cryftals is confiderably diminithed, there is perceived, upon breaking them, a confiderable number of fmall cavities in their fubftance. Thefe cavities are analogous to thofe which appear in the cryftals of the fpathofe ores of iron when they have paffed into a fimilar ftate of decompofition.

\section{Species II. Cupreous Arfeniate of Iron.}

The cryftals of this fpecies are of uncommon brilliancy, and are perfectly tranfparent. Their form is a rhomboidal tetraedral prifm, having two of its edges very obtufe, and the other two very acute: but, owing to the minute fize of 
thefe cryftals, I have not yet been able to determine the meafure of their angles. The prifm is terminated at each of its extremities by a tetraedral pyramid, which is pretty tharp; and its planes, which are fcalene triangles, unite by pairs, forming elongated ridges, which join the acute edges of the prifm : in the other direction, they unite, alfo by pairs, fo as to form a ridge which is lefs elongated, and joins the obtufe edges. Very often the obtufe edges of the prifm are replaced by planes (of greater or lefs extent) equally inclined upon the adjacent ones. (Fig. 3I.) Sometimes the acute edges are alfo replaced in the fame manner, but always by planes of lefs extent. (Fig. 32.)

The above are the only varieties I have obferved of this arfeniate. Its cryftals feldom occur fingly, being generally grouped together, in a very irregular manner; fometimes, however, they are fo united as to affume a mamillated form, having the pyramids of the cryftals which compofe the mamilla all placed upon the furface thereof.

The fpecific gravity of this arfeniate is 3,400 .

Its hardnefs is rather greater than that of the fimple arfeniate of iron: it fcratches calcareous fpar with greater facility, but does not fcratch fluor fpar, or heavy fpar.

Its colour is that of a very faint $\mathrm{ky}$-blue; fometimes the blue colour is a little deeper. I have feen fome cryftals which had the fame brown refin colour as the preceding fpecies; but they are very rare.

Hitherto I have never met with this fpecies in any other form than that of a perfect cryftal.

XXVI. Analyfis of the Arfeniates of Copper and of Iron. By Richard Chenevix, Efq. F.R.S. M.R.I.A.*

\section{SECTION I.}

7 Arfeniates of Copper.

HE endlefs diverfity which the hand of Nature has diffufed through all her works, even when the makes ufe of the fame primitive materials, muft fufficiently convince us, that, whatever accuracy we may attain in the knowledge of the latter, the means which the employs to form her combinations are ftill fecret. The intellectual eye may indulge in the contemplation of hypothetic fyftems, which itfelf has created, and which it alone can behold; but how far removed

* From Tranjaltiens of the Rojal Society of London for $\mathbf{2} 80 \mathrm{r}$. 